\title{
Localización histórico-geográfica de las tierras explotadas por la familia de Cristóbal Colón en el puerto de San Juan (Huelva, España)*/
}

\author{
Historical-Geographical Location of Lands Exploited \\ by the Family of Christopher Columbus \\ in the Port of San Juan (Huelva, Spain)
}

David González Cruz

ORCID iD: http://orcid.org/0000-0002-2078-7192

Universidad de Huelva

Este trabajo de investigación presenta como novedad la localización geográfica concreta de lugares que fueron partícipes del proceso de gestación del descubrimiento de América. Además, confirma la vinculación de la portuguesa Briolanja Muñiz —cuñada de Cristóbal Colón - con el puerto de San Juan (Huelva, España) y, al mismo tiempo, ofrece datos inéditos sobre los límites de la finca en la que estaba asentada la familia del famoso descubridor mientras que gestionaba y organizaba su primer viaje ultramarino.

Palabras clave: Cristóbal Colón; Descubrimiento; América; Briolanja Muñiz; San Juan del Puerto (Huelva); Río Tinto.

This research presents as novelty the geographical location of certain places that were part of the process of gestation of the discovery of America. In addition, it also confirms the linking of the portuguese Briolanja Muñiz — sister in law of Christopher Columbus - with the port of San Juan (Huelva, Spain), and at the same time, offers unpublished data on the boundaries of the estate where the family of the famous discoverer was seated while he managed and organized his first overseas trip.

Keywords: Christopher Columbus; Discovery; América; Briolanja Muñiz; San Juan del Puerto (Huelva); Tinto river.

Copyright: (C) 2017 CSIC. Este es un artículo de acceso abierto distribuido bajo los términos de una licencia de uso y distribución Creative Commons Attribution (CC-by) España 3.0.

* La realización de esta investigación ha dispuesto de una ayuda económica concedida al Grupo de Investigación «Mentalidad, sociedad y medioambiente en Andalucía e Iberoamérica» (HUM-785) por el Plan Andaluz de Investigación con financiación de la Junta de Andalucía y de los fondos FEDER de la Unión Europea. 


\section{Introducción}

Evidentemente la historiografía que ha estudiado los viajes colombinos ha avanzado de manera notable durante el siglo XX y comienzos del XXI en el progresivo conocimiento de lo acontecido en los inicios de la Edad Moderna en los puertos de Andalucía occidental; aun así, la escasez de fuentes no ha permitido efectuar en todos los casos un análisis exhaustivo de cada acontecimiento, lugar o personaje relacionado con la gestación del descubrimiento de América ${ }^{1}$ en el triángulo formado por los estuarios de los ríos Tinto y Odiel. A pesar de ello, y siendo consciente de las limitaciones que suele imponer la documentación histórica de esta época, el objetivo de esta investigación pretende continuar aportando datos inéditos que contribuyan a arrojar nuevas luces sobre algunos de los protagonistas de las relaciones que pudieran haberse tejido en el espacio denominado como «Lugares Colombinos», así como sobre el entorno geográfico donde pudieron haberse desarrollado; más concretamente el estudio se ha centrado en el Puerto de San Juan — primer nombre dado a esta población por el duque de Medina Sidonia en la carta puebla otorgada el 10 de enero de 1468-. Precisamente, se trata de una localidad que había quedado al margen de la mayoría de los trabajos realizados hasta el momento presente sobre los viajes colombinos y su organización —-salvo algunas excepciones, como es el caso de las investigaciones efectuadas por Consuelo Varela y David González_- ${ }^{2}$ y ello como consecuencia de la parquedad de las fuentes y como resultado de la pérdida de casi la totalidad de la documentación del Archivo Municipal de San Juan del Puerto correspondiente a fines del siglo $\mathrm{XV}$ y primeras décadas del siglo XVI. ${ }^{3}$ En este sentido, partiendo de la base de que el río Tinto fue la arteria principal de comunicación de los personajes que prepararon la primera expedición a América en las localidades de

1 En este artículo se ha utilizado la palabra «descubrimiento» atendiendo a la terminología empleada por los contemporáneos de la época de los viajes colombinos.

2 Entre ellas pueden mencionarse las siguientes publicaciones: Varela, 1988 y 1992. González Cruz, 2012 y 2016.

3 Solamente se aprecia la existencia, en el mencionado Archivo Municipal de San Juan del Puerto, de varios privilegios relativos a la época del descubrimiento de América que fueron copiados en el documento de la concesión del título de villa por el duque Juan Claro de Guzmán el 15 de julio de 1551, así como alguna documentación concreta referente a pleitos y litigios mantenidos con municipios de su entorno. Concretamente, las actas capitulares comienzan en el año 1583, teniendo algunas lagunas documentales en determinados periodos de fines del siglo XVI y primeras décadas del XVII, por tanto se ha perdido la constancia documental de los acuerdos de los cabildos capitulares de fechas anteriores, es decir de los siglos XV y XVI. 
ambas orillas, parecía extraño que la historiografía tradicional solamente hubiera hecho referencia a tres de los puertos de su estuario (Palos de la Frontera, Moguer y Huelva) y casi nunca al cuarto (San Juan); en este marco, los resultados del trabajo de investigación que ahora es objeto de esta publicación tienen la virtualidad de seguir perfilando el círculo de interrelaciones entre las dos riberas de los Lugares Colombinos de la provincia de Huelva contribuyendo así a formar una imagen global de ellos en tiempos de las exploraciones descubridoras. Desde luego, el estudio de la vinculación geográfica de Briolanja Muñiz — cuñada de Cristóbal Colón— con el puerto de San Juan no parece que sea una cuestión menor a tener en cuenta en el análisis de un acontecimiento cuya armada se preparó en estas tierras y que ha tenido una evidente trascendencia en la historia de la humanidad.

En cualquier caso, la tarea propuesta resultaba atractiva, pero al mismo tiempo la mencionada parquedad de las fuentes exigía hacer un seguimiento de ellas hasta el más mínimo detalle para proceder en una segunda fase a un cruzamiento de documentos muy diversos que permitieran revelar determinados «silencios aparentes» contenidos en los papeles de archivo y en los recursos topográficos o de planimetría utilizados. Por tanto, las conclusiones y las aportaciones de este artículo proceden, principalmente, del conjunto de interrelaciones que de manera continuada se han realizado entrelazando con todo el rigor posible la variada tipología de fuentes; entre ellas, las existentes en los fondos del Archivo General de la Fundación Casa Medina Sidonia, Archivo General de Indias, Archivo General de Simancas, Archivo Municipal de San Juan del Puerto y en la sección de protocolos notariales del Archivo Histórico Provincial de Huelva; a ellas se unirían determinadas ordenanzas señoriales y reales provisiones, diferentes colecciones documentales sobre el descubrimiento de América, los pleitos colombinos, crónicas y obras historiográficas, testimonios orales sobre topónimos referentes a lugares del término municipal de San Juan del Puerto, así como diferentes planos hallados en el Museo Naval (Madrid) u otros elaborados por el Instituto Geográfico y Estadístico de España. En fin, esta ardua labor de investigación dilatada durante varios años que ha ido conexionando acontecimientos, lugares, personajes, testigos, e indicios nos posibilita ahora presentar los avances conseguidos, lo cual no supone que en el futuro - cuando obtenga nuevos datos e informaciones relevantes- no continúe progresando en el análisis del papel que desempeñaron los puertos del Tinto en los viajes descubridores en los que tuvieron una participación efectiva los marinos y residentes en ambas orillas. Con todo, para empezar 
habría que ocuparse del estudio del lugar que fue referente geográfico para Colón y foco de atracción familiar para su venida a las tierras y puertos suroccidentales de Andalucía.

\section{Localización y límites de las tierras explotadas por la hermana de la esposa de Colón}

García Fernández, físico de Palos, quien tuvo la oportunidad de conocer a Cristóbal Colón en el estuario del río Tinto, habló con él y participó en sus conversaciones con los frailes de La Rábida con anterioridad al descubrimiento del «Nuevo Mundo», dejó registrado en su testimonio de los pleitos colombinos una razón — según sus propias palabras - de la presencia del descubridor en estas tierras occidentales del reino de Sevilla; no en vano, declaraba en las probanzas del fiscal que «se vino de la corte e se yva derecho desta villa [de Palos] a la villa de Huelva para fablar e verse con un su cuñado casado con hermana de su mujer e que a la sazón estava e que avía nombre Mulyar». ${ }^{4}$ Desde luego, el médico palense, ${ }^{5}$ uno de los interlocutores de Colón en la zona y conocedor de sus intenciones, confirmaba la función que tuvieron sus parientes en la configuración geográfica de la ruta colombina seguida durante el proceso de gestación del descubrimiento de América. En esta misma línea se pronunciaba Bartolomé de Las Casas cuando afirmaba que acudió al «monasterio de La Rábida, de la Orden de sant Francisco, que está junto a aquella villa, con intinción [sic] de pasar a la villa de Huelva a se ver con un concuño [sic], casado diz que con una hermana de su mujer». ${ }^{6}$

En principio, la mención de García Fernández a que el genovés iba en dirección hacia Huelva nos ha llevado a investigar las referencias a sus cuñados en las fuentes demográficas de esta villa; si bien tras el estudio de la documentación disponible no se ha encontrado evidencia alguna de que estuvieran avecindados o residieran en ella antes de 1492, no se puede descartar totalmente esta posibilidad. En este sentido, el primer padrón conocido fue elaborado en 1503 por la administración ducal, pero en esa

4 Muro, 1989, 245.

5 El término «palense» es el que se encuentra aceptado por el Diccionario de la Real Academia de la Lengua Española; sin embargo, los habitantes de Palos de la Frontera y los residentes en todo su entorno comarcal utilizan la palabra «palermo» para referirse a la persona que es vecina de esta villa.

6 Las Casas, 1994, 512. 
fecha Miguel Muliart ya había fallecido y Briolanja Muñiz, su cónyuge, se encontraba residiendo en la ciudad de Sevilla; en cualquier caso, no quedaron registrados en el mencionado padrón. Por otra parte, el hecho de que los Reyes Católicos hubieran concedido el 30 de mayo de 1493 al matrimonio Muliart-Muñiz una casa en Huelva ${ }^{8}$ procedente de los bienes confiscados a Bartolomé de Sevilla ${ }^{9}$ - acusado del «delito de herejía»— para que la usufructuasen en la modalidad de «secuestro», podría indicar también - solamente como una posibilidad- que hasta ese año no dispusieron de una vivienda en esta localidad, ${ }^{10}$ aunque para entonces figuraban en el documento como vecinos de Sevilla tras haberse producido el descubrimiento de América. Con todo, no sería hasta el 24 de octubre de 1496 cuando obtuvieron la posesión definitiva de la casa y de todos los bienes correspondientes a la citada persona que fue enjuiciada por el tribunal del Santo Oficio de la Inquisición, ${ }^{11}$ a excepción del derecho de tercias disfrutado por el duque de Medina Sidonia en las tierras de su jurisdicción; así lo expresaba el documento otorgado por los monarcas:

Don Fernando e Doña Ysabel [...] por fazer bien e merçed a vos Briolanja Muñiz, muger de Miguel Muliarte, difunto, vezino de la çibdad de Sevilla, acatando los muchos e buenos servicios quel dicho vuestro marido e vos nos aveys hecho [...] en remunerazión dellos [...] vos fasemos merçed [...] no revocable agora e todo tiempo e syempre jamás de todos los bienes muebles e rayses e semovientes que fueron [...] de Bartolomé de Sevilla e de Elvira Gonçalez, su mujer, vecinos que fueron de la villa de Huelva e fueron confiscados [....$^{12}$

7 Curiosamente su muerte se produjo durante el segundo viaje colombino y como consecuencia del tormento sufrido por mandato de Cristóbal Colón. Varela, 2006, 126.

8 Es de suponer que la merced de otorgarle esta posesión procedería de una petición efectuada por Cristóbal Colón a los Reyes Católicos si se tiene en cuenta que recibieron al Almirante en Barcelona en el mes de abril de 1493, poco antes de materializar esta decisión mediante una real cédula.

9 En torno a este encausado del Santo Oficio puede verse también: Gil, 2001, 269.

10 Así reflejaba esta merced en una real cédula dirigida a los inquisidores de Sevilla: «Devotos padres ynquisidores de la herética pravidad de la çibdad de sevilla e su arçobispado. Nos vos encargamos en mandamos que los bienes muebles e rayzes que fueron de bernabé de Sevilla vecino de huelva e por vuestro mandado están secrestados en poder de diego Alonso escrivano vecino de la dicha villa de huelva los pongays en secrestaçión de miguel muliert vecino de la dicha çibdad de sevilla e briolante Muñiz su muger para que los ellos tengan en secresto hasta que su cabsa sea determinada non permitays que dellos disponga el nuestro reçebtor cosa alguna syn primero nos lo faser saber e veays nuestro mandamiento [...] De Barcelona a XXX de mayo de XCIII años». Pérez de Tudela, 1994, 418.

11 El secuestro y confiscación de los bienes de Bartolomé de Sevilla tendría lugar como consecuencia de la actividad inquisitorial promovida por los Reyes Católicos en el Condado de Niebla mediante una real provisión dictada el 8 de febrero de 1491 mientras se encontraban en la ciudad de Sevilla. Anasagasti y Rodríguez, 2006, v. 2, 953-955.

12 Archivo General de Simancas, Registro General del Sello, leg. 149610, f. 5. 
Con todo, los datos analizados apuntan a que no hay certeza de una residencia permanente de los cuñados de Colón en la villa de Huelva antes de 1492; a este respecto, el padre Ortega exponía su tesis de que la estancia de Miguel Muliart en esta localidad era «transitoria y accidental» y que la frase del médico palense indicando «que a la sazón estaba» ${ }^{13}$ en ella solamente significaba que entonces, por aquellos días, se encontraba en Huelva, aunque al mismo tiempo consideraba que no había morado previamente en ningún lugar de la comarca como consecuencia de no haber encontrado fuentes que probasen su vinculación con estas tierras. ${ }^{14}$

Sin embargo, el hallazgo de nuevos documentos ha permitido demostrar fehacientemente una relación continuada de Briolanja Muñiz con San Juan del Puerto. Así la doctora Consuelo Varela halló un apunte de contabilidad referente al año 1493 que registraba el arrendamiento de tierras que le hizo el duque de Medina Sidonia en San Juan: $;{ }^{15}$ posteriormente, en el curso de mis investigaciones, descubrí que en un privilegio otorgado a los vecinos de este lugar se mencionaba expresamente a esta noble portuguesa, demostrándose de este modo que la explotación del terreno arrendado se produjo con toda seguridad antes del primer viaje colombino, concretamente la fecha exacta podría situarse entre 1484 y 1492, puesto que en el citado documento se aprecia que el ejido comunal concedido en un principio al concejo municipal del puerto de San Juan estaba en poder de la hermana de la esposa de Cristóbal Colón, como mínimo desde 1492, y muy posiblemente en años anteriores, por decisión del duque Enrique de Guzmán, quien había privado a los vecinos de este privilegio que le fue otorgado en 1484. De ello se hacía eco su hijo Juan de Guzmán cuando mencionaba la petición de los sanjuaneros de que les restituyese

la tierra de que el Duque, mi señor, y mi padre (que santa gloria haia) hizo merced a Vriolanja Muñiz, para Exido de dicho Conzexo, como antes lo era, por ser cosa mui necesaria, e provechosa así al pro común de mis vasallos, como para las bestias de los requeros que vienen a ese mi lugar. ${ }^{16}$

No obstante, a pesar del traslado a Sevilla de Miguel Muliart y Briolanja, en los años siguientes a 1493 esta finca de antiguo aprovechamiento

13 Muro, 1989, 245.

14 Ortega, 1925, 366-367.

15 Libro de rentas mayores y menores del Condado de Niebla, San Juan del Puerto, 1493, Archivo de la Fundación Casa Medina Sidonia (AFCMS), 2.428, f. 24v. Varela, 1988, 99.

16 Privilegio otorgado por el duque de Medina Sidonia a San Juan del Puerto el 20 de enero de 1493, AFCMS, 736, s/f. 
comunal continuó siendo arrendada a particulares por parte de la casa ducal; aun así, el reconocimiento social y la notoriedad que consiguió la cuñada de Colón en el condado de Niebla - especialmente después del descubrimiento de América - contribuiría a que los contadores y los administradores del duque reflejasen en la contabilidad de las rentas de la casa de Medina Sidonia correspondientes a los años 1493, 1494, 1495 e, incluso, 1513, que las mencionadas tierras habían sido cultivadas previamente por Briolanja Muñiz; ${ }^{17}$ ciertamente, se trataba de una mención identificativa que no era precisa a efectos económicos atendiendo a que el arrendamiento había pasado a manos de otras personas.

Una vez confirmada la vinculación de la familia de Cristóbal Colón con San Juan del Puerto a través de los estudios realizados por Consuelo Varela y David González, parecía francamente difícil avanzar en la investigación de manera que pudiera hallarse el lugar concreto donde se encontraba la finca referida, y ello a pesar de tratarse de un emplazamiento de referencia en el periodo de la gestación del descubrimiento de América, si se tiene en cuenta - tal como afirmaban testigos directos- que el famoso navegante llegó desde la corte al estuario del río Tinto para encontrarse con sus parientes. Desde luego, la empresa se presentaba complicada considerando que ni el privilegio de 20 de enero de 1493 ni los libros de rentas de la casa ducal delimitaban el sitio exacto de las tierras arrendadas. Con todo, el cruzamiento de estos datos con el privilegio concedido por Enrique de Guzmán a los vecinos de San Juan el 22 de septiembre de 1484, por el que les dotaba de ejido, ofrecía algunas pistas no determinantes sobre su ubicación, pero que precisaban ser estudiadas con detalle; precisamente, como podemos comprobar, el mencionado privilegio reseñaba los límites de esta finca:

Primeramente es mi merced e voluntad que vos sea dado por exido a ese mi lugar para proveimiento de las bestias del pueblo e de los recueros que ende vinieren a comprar o vender qualesquier cosas para que coman con sus bestias, franca e sensatamente, desde el estero de Juan de Coto fasta una retamera donde se hizo un mojón cubierto, e de allí que va a dar al primero alcornoque parde el montezillo como van de San Juan para Trigueros, e de allí que buelva por de frente del lugar por otro alcornoque e mojones quel dicho Diego de Ayón fizo señalar e amojonar, e de allí vaya a dar a otro mojón en campo Raso, questá de frente de la huerta de Ruy López que va a dar a un alcornoque questá de frente la tierra de la compañía, e de ay buelva a la redonda cercando el lugar a un alcornoque, el más gordo de todos, e dende va a dar al carril que va del dicho logar a Trigueros e atraviesa el dicho carril e va a dar a una lantisca questá a mojón

17 Libros de rentas de la Casa de Medina Sidonia, 1493-1513, AFCMS, 2.428 (f. 24v, 78v, $121 \mathrm{r})$, y 2.429 . 
cubierto en el camino que va del dicho lugar a Niebla. Por los quales dichos mojones e alcornoques quedose señalado e amojonado el dicho exido $[\ldots] .{ }^{18}$

A pesar de la información expresada en el documento anterior, los lugares de referencia no permitían establecer una clara conexión con la denominación utilizada actualmente ni con la vegetación o masa forestal existente en nuestros días; en efecto, los alcornoques, los lenticos, la mojonera, el ejido, o la denominación de un estero reseñado en el privilegio transcrito previamente habían quedado obsoletos para la memoria colectiva de los sanjuaneros e, incluso, en gran parte de la planimetría reciente; por tanto, después del intento de obtener testimonios orales de trabajadores del campo de edad avanzada, ya jubilados en su mayoría, todo parecía indicar que quedaba por delante una ardua investigación para localizar con exactitud este lugar colombino. Pese a ello, he perseverado durante varios años en la búsqueda de la documentación que posibilitara rastrear nuevos indicios que llevaran al objetivo final; de esta forma, he realizado determinadas averiguaciones en el Archivo Municipal de San Juan del Puerto, en los protocolos notariales del Archivo Histórico Provincial de Huelva, en los libros de fincas del Catastro de Ensenada y en el Archivo General de la Fundación Casa de Medina Sidonia, que unidas al análisis topográfico, al cruzamiento con fuentes orales, a algunas huellas arqueológicas y también mediante planos elaborados en el periodo que va desde el Antiguo Régimen hasta el siglo XX han permitido identificar los principales referentes utilizados a fines del siglo XV por Diego de Ayón — corregidor, justicia mayor y caballero de la casa ducal- para la delimitación de este espacio geográfico. Entre los mencionados referentes analizamos a continuación el emplazamiento del estero de Juan de Coto, el sitio de El Montecillo, los registros documentales conservados sobre la extensión del citado ejido en la Edad Moderna, así como los restos arqueológicos inventariados.

\section{El estero de Juan de Coto}

El conocimiento de la situación geográfica de este estero ha sido complejo dada la evolución de su nomenclatura a lo largo de los últimos cinco siglos y, por ello, ha requerido de un estudio de detalle mediante el manejo de documentación de diversa procedencia. La principal dificultad ha

18 Archivo Municipal de San Juan del Puerto (AMSJP), 43. Una copia se halla transcrita con todo su contenido en González Cruz, 1992, 35-36. 
residido en que su consideración nominal como estero no se ha conservado hasta nuestros días como consecuencia directa de las obras de infraestructura realizadas por las compañías ferroviarias de Rio Tinto, Buitron y M.Z.A. durante los siglos XIX y XX. Ciertamente, la colocación de vías férreas en el término municipal de San Juan del Puerto contribuyó a dividir el estero en dos partes reduciendo la afección de la subida y bajada de las mareas del estuario del río Tinto hasta el punto que ha terminado desecándose para convertirse, en apariencia, todo el cauce del estero en una prolongación del arroyo llamado de Ruy Lorenzo, ${ }^{19}$ al que con posterioridad se le dio el nombre de arroyo del Prado o arroyo de la finca de La Habana - esta última es la denominación más extendida actualmente entre los habitantes de San Juan del Puerto-.

En todo caso, para su exacta ubicación ha sido especialmente relevante el hallazgo de un documento relativo al arrendamiento del molino mareal que era propiedad de María Magdalena García Valladares, ya que en esta escritura notarial se menciona el estero de Juan de Coto, donde estaba instalado el citado molino, así como el que se hallaba más cercano a él hacia el este, el estero de Berjillos — conocido actualmente por los sanjuaneros como Brejillo debido a la evolución lingüística de su expresión coloquial—. ${ }^{20}$ De igual modo, se indica la obligación de los arrendatarios de construir un estero nuevo hacia el sitio de la Alquería ${ }^{21}$ (hacia el oeste, en un espacio de la marisma en dirección al término municipal de la vecina localidad de Huelva); por tanto, es evidente que el estero Juan de Coto quedaba en medio de ambos transcurriendo su cauce por el centro de la finca llamada actualmente como La Habana. Desde luego, los fragmentos de la escritura de arrendamiento consultada en el Archivo Histórico Provincial

19 Con este nombre se menciona al citado arroyo en los libros de fincas eclesiásticas y seculares del Catastro de Ensenada correspondientes al término municipal de San Juan del Puerto. AMSJP, 493 y 494. Por otra parte, entre los trabajadores del campo de San Juan del Puerto — según los testimonios orales manejados - la denominación ha evolucionado en el uso del lenguaje hasta llamarle río Lorenzo, pues se ha podido atestiguar que se ha transformado el nombre de «Ruy» en «río».

20 Una parte importante del estero de Berjillos se situaba, desde siglos anteriores, en el lugar que actualmente ocupa la avenida Andalucía, pues hace varias décadas que este sector que transcurría por el núcleo urbano de San Juan del Puerto fue canalizado a través de tuberías y pavimentado para el tránsito de vehículos y personas; solamente se conserva en su estado original un tramo de este estero, concretamente el que circunda las instalaciones de las antiguas bodegas Lazo que se encuentran en las proximidades del río Tinto y de la estación de ferrocarril de esta localidad.

21 No tenemos constancia documental de que este último estero se llegase a realizar de manera artificial y si su emplazamiento en la marisma en dirección a La Alquería pudo condicionar su ejecución definitiva, ya que su entorno estaba inmerso en una disputa entre los cabildos municipales de Huelva y San Juan del Puerto que condujo a un pleito judicial en el siglo XVIII. 
de Huelva, concretamente en los protocolos notariales del escribano Antonio Torneo de los Ríos correspondientes a 1773, no dejan lugar a dudas respecto a su identificación:

Digo yo $D^{a}$. María Magdalena García Valladares, vecina de esta villa de San Juan del Puerto $[\ldots]$ doi arrendamiento vitalicio por tiempo de quattro años [...] hasta el día treinta y uno de octubre de mil settecientos sesenta y siette, es a saber un molino pan moler, que tengo en la ribera del río de esta villa, en el estero que dicen de Coto, a el qual molino llaman regularmente el de D. Agustín [...] Ytt. con condición, que durante el tiempo de dichos quatro años an de abrir un estero nuebo a su costa en la marisma, hacia el lado de la Alquería, el que a de ttener quando menos tres varas de ancho, y quattrocienttos de largo, con el hondo correspondiente para que reciba, y bacie el agua [...] Ytt. como condición que durante dichos quatro años an de ser obligados dichos arrendadores a limpiar el estero de Berjillos, y la caldera de un golpe de pala, y cumplido dicho arrendamiento no aviéndolo practticado lo e de poder hacer a su costa y por su importte $[\ldots] .{ }^{22}$

Por otro lado, la pervivencia de la denominación de Coto en el siglo XVIII también se aprecia en el libro de fincas seculares del Catastro de Ensenada cuando se alude a una propiedad de tierra de secano situada en el sitio llamado del Bermejal, que según testimonios orales obtenidos ${ }^{23} \mathrm{se}$ confirma que coincide con unos terrenos que están en las proximidades del mencionado estero; así se puede comprobar en la descripción efectuada a mediados del setecientos sobre la siguiente parcela:

tierra de dos fanegas y tres quartillas de sembradura de secano de primera calidad; a el sitio del Bermejal, distante de la población un tiro de vala: confronta [...] al Norte con el camino de Huelva; y al Sur con el estero que nombran el Coto [... ${ }^{24}$

En el fragmento del plano de San Juan del Puerto (figura 1) se observa perfectamente que el estero Juan de Coto transcurría por la finca La Habana y enlazaba con un arroyo antes de efectuarse las obras por parte de las diferentes compañías ferroviarias a fines del siglo XIX y principios del XX, ${ }^{25}$

22 Contrato de arrendamiento firmado en San Juan del Puerto el 28 de octubre de 1773, Archivo Histórico Provincial de Huelva (AHPH), Protocolos Notariales de San Juan del Puerto, 5.184, f. $592 \mathrm{r}-595 \mathrm{v}$.

23 Información topográfica proporcionada por Rafael García Gómez, vecino de San Juan del Puerto y trabajador del campo, que frecuentó a mediados del siglo XX esos terrenos, y que atestigua se les daba la denominación de Bermejal.

24 Libro de fincas seculares del Catastro de Ensenada, San Juan del Puerto, 1752, AMSJP, 493, f. 624.

25 En torno a una información más amplia sobre las infraestructuras construidas por estas compañías puede verse: Romero, 2007, 590. Ramírez, 1992, 211-233. 


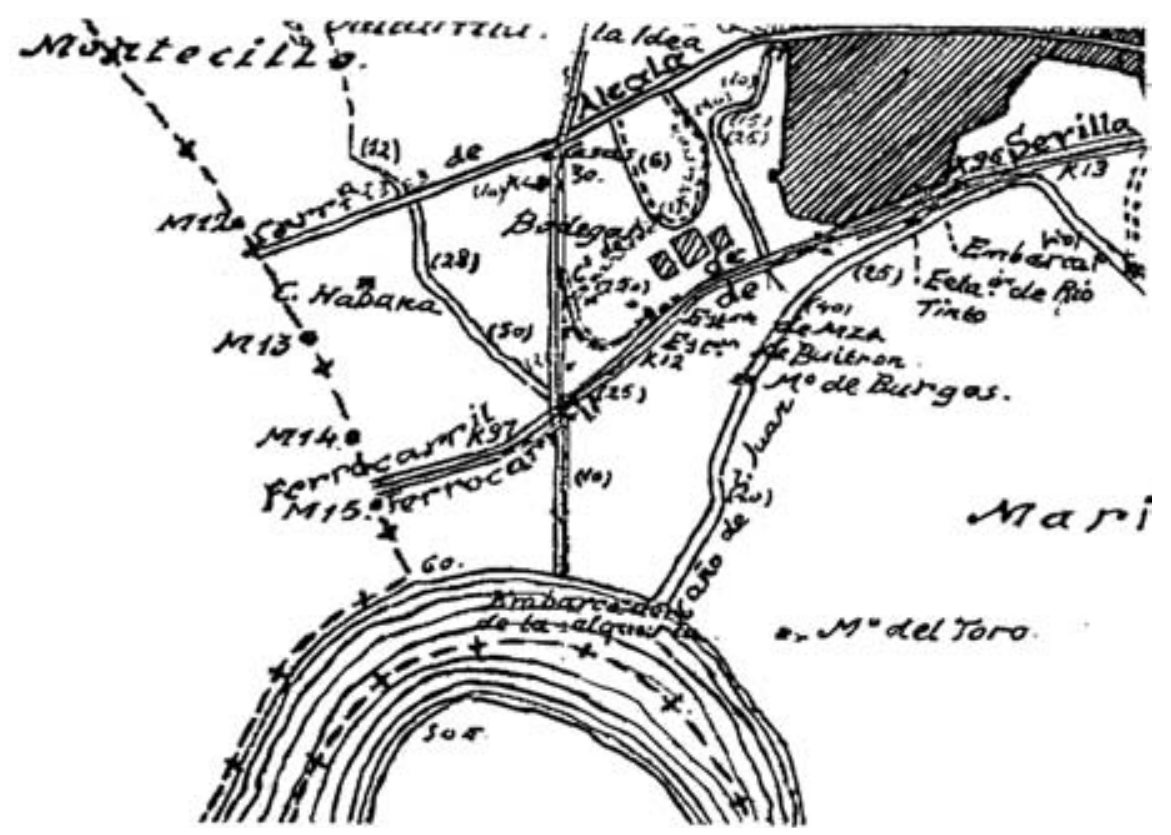

Figura 1. Detalle del plano correspondiente al término municipal de San Juan del Puerto, elaborado en 1898 por el Instituto Geográfico y Estadístico (España), según los bosquejos de planimetría mandados formar por la ley de 24 de agosto de 1896. Escala de 1:25.000.

así como consecuencia de la construcción de la carretera nacional A-472 (Huelva-Sevilla); no en vano, se advierte que confluían en su cauce los diferentes trazados de las líneas ferroviarias de Rio Tinto Company Limited, The Buitron \& Huelva Railway \& Mineral Co. Ltd.y la M.Z.A. en su tramo Huelva-Sevilla. Asimismo, hacia el este se aprecia el cauce del estero Berjillos, situado entre las bodegas de Lazo y las últimas viviendas del núcleo urbano de la localidad, siendo cruzado igualmente por la carretera nacional A-472 y los trazados ferroviarios de Rio Tinto Company Limited y M.Z.A.

Sea como fuere la evolución de este estero, lo cierto es que desde la época de la fundación del puerto de San Juan adoptó la denominación de una persona concreta, al igual que otro de los esteros más conocidos del estuario del río Tinto que estaba situado cerca del convento de La Rábida y que tomó el nombre de Domingo Rubio. Lógicamente surge el interrogante de quién era Juan de Coto y qué vinculación podría haber tenido con San Juan del Puerto. Aunque es imposible tener la certeza absoluta de que 
no hubieran habido dos personas con este mismo nombre, parece viable que estuviera ligado a la figura de un capitán de una carabela llamado exactamente así que participó en la expedición a Guinea organizada por Charles de Valera ${ }^{26}$ en 1476 - entonces tenía la condición de vecino de Moguer-; en el caso de que hubiera sido de este modo se trataba de un marino experto que podría haber utilizado el estero como un lugar de referencia para sus actividades marítimas, sobre todo teniendo en cuenta que estaba localizado frente al puerto moguereño de La Ribera, a escasa distancia aunque en la orilla opuesta. También consta documentalmente que el apellido Coto pertenecía, al menos, a una familia integrada en la élite local; no en vano, se ha podido atestiguar, en una escritura otorgada en 1481, que el alcalde de Moguer en esa fecha era Gonzalo de Coto. ${ }^{27}$ También se ha constatado la existencia de un Gonzalo Pérez de Coto, vecino de Moguer (podría ser la misma persona que el anterior e, incluso, un pariente), que tenía concertada en 1490 una compañía con el mencionado Charles de Valera —alcaide del Puerto de Santa María- y con el capitán Bartolomé Leytes — también vecino de la citada localidad gaditana-, con quienes mantuvo una disputa por no haberles entregado la parte que le correspondía por el apresamiento de una embarcación musulmana que se dirigía al reino de Granada. ${ }^{28}$

\section{El Montecillo}

La ubicación de este lugar en las proximidades del estero de Juan de Coto reafirma la identificación que se ha efectuado previamente, puesto que precisamente el sitio de El Montecillo se trata de una elevación de terreno de escasa altitud situado en las proximidades del río Tinto y, por tanto, su configuración es el resultado de la evolución geológica de su cauce y del propio estero. Desde luego, el emplazamiento de las tierras explotadas por Briolanja Muñiz era privilegiado por encontrarse cercano a las instalaciones portuarias de San Juan del Puerto y al camino que unía a esta localidad con Huelva; concretamente, la propiedad que le arrendó el duque de

26 En la citada expedición participaron cuatro embarcaciones mandadas por moguereños: la carabela de Juan de Burgos estuvo capitaneada por Juan Quintero, la de Juan de Boria mandada por él mismo, la de Lope Ruíz por Rodrigo Quintero y la de Juan de la Plaza por Juan de Coto. Aznar, 2002, 408,416 y 422.

27 Escritura sobre la delimitación de los términos de los concejos de Moguer y Palos, otorgada el 13 de octubre de 1481, Archivo Municipal de Moguer (AMM), Pergamino n. ${ }^{\circ} 25$ del Libro de Privilegios. González Gómez, 1977, 268.

28 Ibidem, 146. 


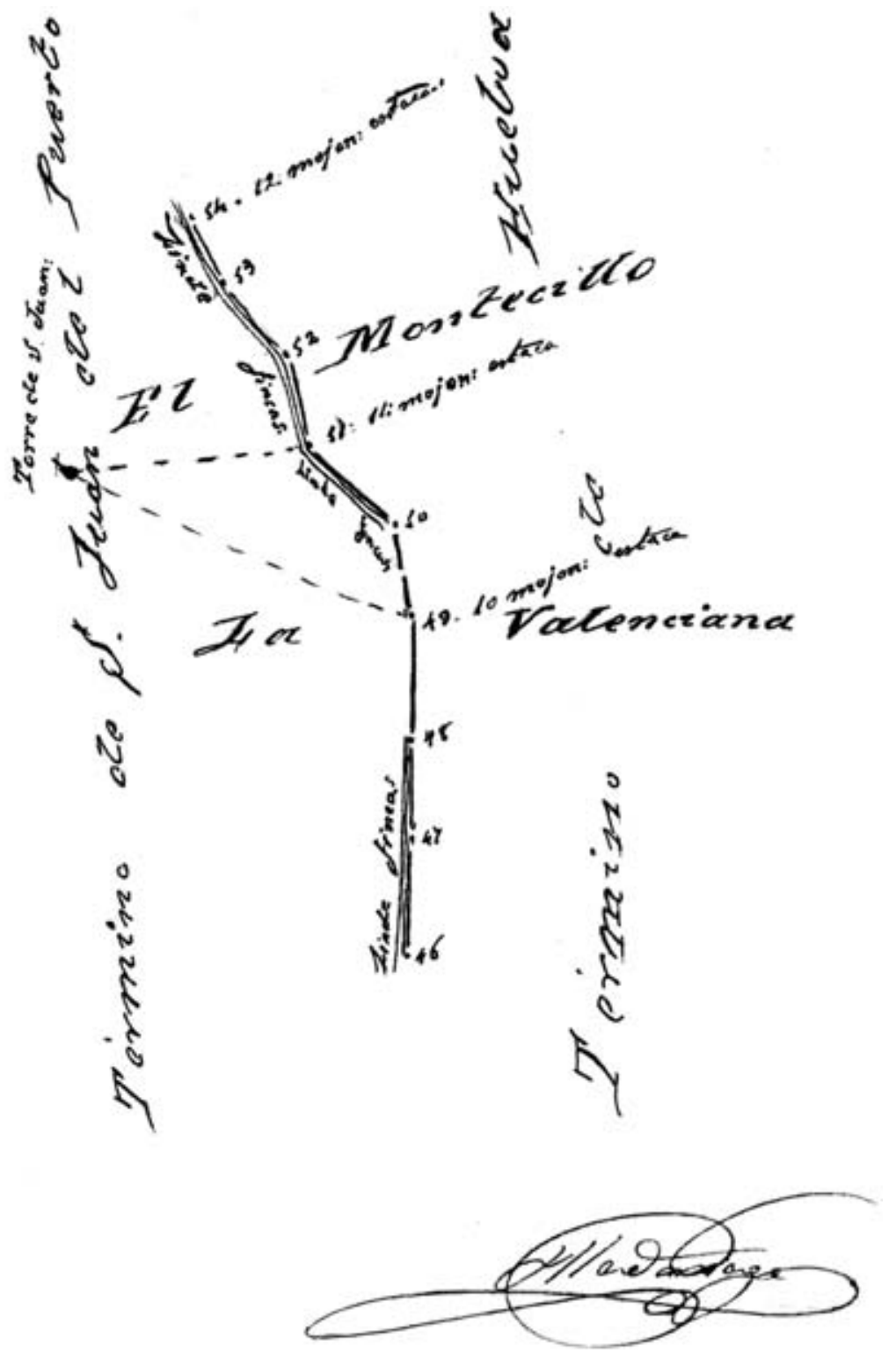

Figura 2. Bosquejo de planimetría del lugar El Montecillo, realizado por José de Madariaga el 18 de mayo de 1898; marca el límite de los términos municipales de Huelva y San Juan del Puerto. Instituto Geográfico y Estadístico (España), Cuaderno 1898-106088. 
Medina Sidonia se hallaba justamente en el límite con el término municipal de Huelva. Por ello, tampoco es de extrañar que Cristóbal Colón fuese en dirección a Huelva en la búsqueda de su cuñado Miguel Muliart, pues desde allí también podía enlazar con el camino que iba a San Juan.

Por otro lado, la descripción que el Catastro de Ensenada efectuaba sobre una finca ubicada en este sitio ratifica su situación limítrofe con el término municipal de Huelva y, por otra parte, la referencia que hacía a la calidad del terreno - de primera calidad-, dedicado al cultivo de cereales, nos confirma que continuó explotándose de la misma forma que en la época colombina, cuando eran arrendados por la casa ducal a cambio de algunos cahices de trigo; en estos términos se describía en el libro de fincas seculares:

otra pieza de tierra a veintte y siette fanegas de sembradura de secano de primera calidad al sitio de Montesillo distantte de la poblazión medio quartto de legua confronta a Levante con el Arroyo que llaman de Rui Lorenzo, a Poniente con la raya de la villa de Huelva [...], produze en dos años una cosecha siette partes de trigo y una de cevada $\left[\ldots . .{ }^{29}\right.$

Asimismo, otro registro documental del mencionado Catastro, en este caso tomado del libro de fincas eclesiásticas, indica que El Montecillo limitaba con el camino que conectaba al puerto de San Juan con la villa de Huelva, al tiempo que corrobora las cualidades de las tierras para su uso agrícola:

otra pieza de tierra de seis fanegas de sembradura de secano de primera calidad a el sitio del Montesillo, distante de la población medio quarto de legua: confronta a Levante con el Arroyo de Ruy Lorenzo [...], y a el Sur con el camino de Huelva, produze en dos años una cosecha, siette parttes de trigo y una de cevada $[\ldots]^{30}$

Por su parte, en el plano de la figura 3 se aprecia de forma evidente la ubicación de El Montecillo junto a tierras de aprovechamiento comunal con la denominación de ejidos y otras fincas llamadas Carrascales, situadas al Norte, que pertenecían al cabildo municipal de San Juan del Puerto; es sintomático que todas ellas hubieran tenido una dimensión colectiva en su origen, al igual que el ejido que fue arrendado por el duque de Medina Sidonia a Briolanja Muñiz, lo cual nos lleva a plantear la hipótesis de que

29 Libro de fincas seculares del Catastro de Ensenada, San Juan del Puerto, 1752, AMSJP, 493, f. $248 v-249$ r.

30 Libro de fincas eclesiásticas, San Juan del Puerto, 1752, AMSJP, 494, f. 197. 


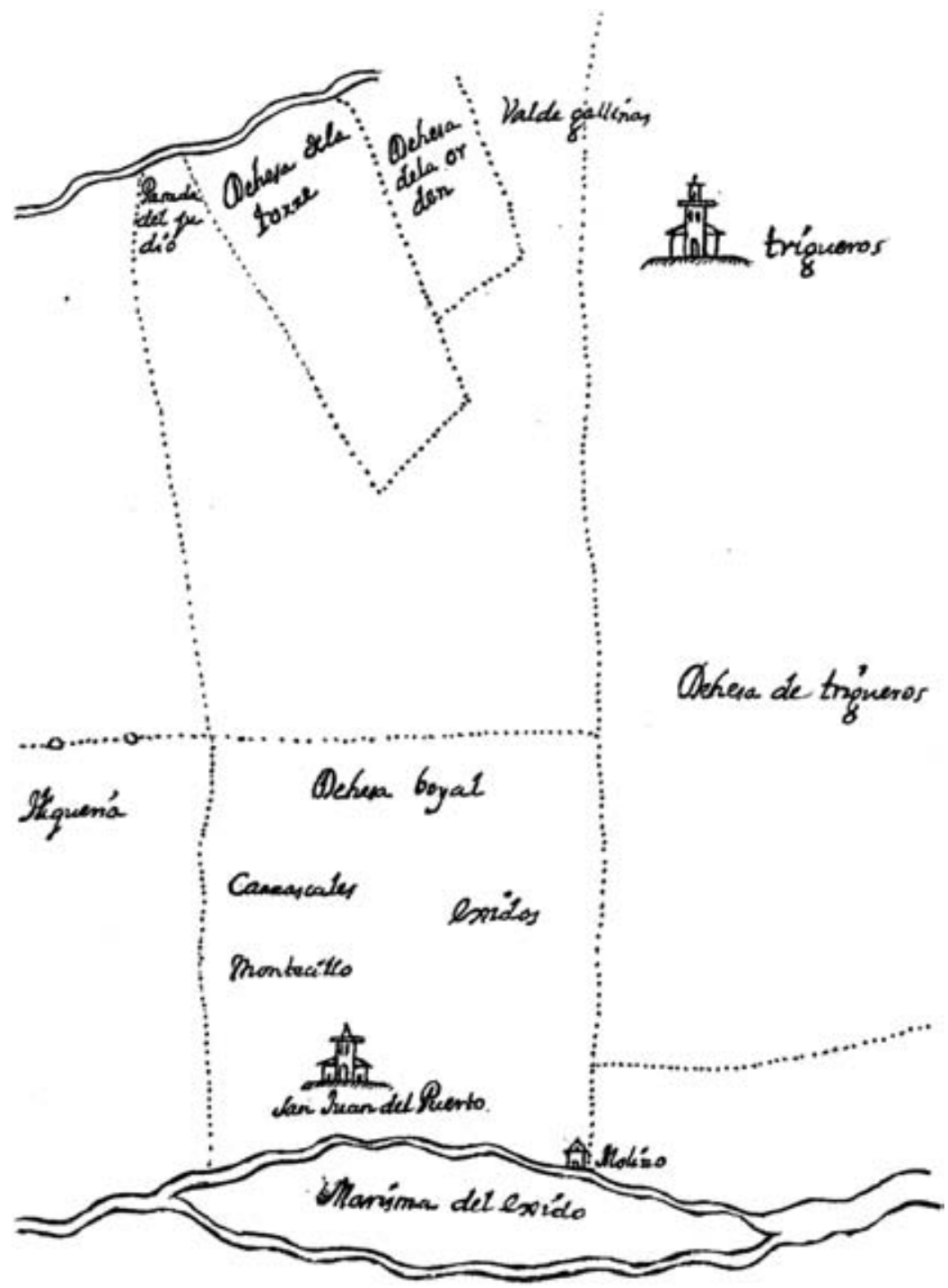

Figura 3. Detalle del término municipal de San Juan del Puerto, extraído del plano más antiguo conservado sobre esta localidad, que incluye los municipios de Huelva, San Juan y una parte de Trigueros. Reseña el lugar de El Montecillo y los ejidos. No se encuentra datado, pero muy posiblemente fue realizado en el siglo XVIII por encontrarse integrado en la documentación elaborada en el mencionado siglo. Archivo General de la Fundación Casa de Medina Sidonia (AFCMS), 1.156. 
antes de la concesión de la carta puebla a los vecinos de San Juan del Puerto la propiedad del conjunto era de titularidad ducal. Precisamente respecto al uso comunitario que se le daba a los Carrascales en favor de los habitantes de la localidad ${ }^{31}$ se dispone de un acuerdo fechado el cinco de septiembre de 1583 , recogido en las primeras actas capitulares que se conservan del municipio, en el que se manifiesta al mismo tiempo una cierta dependencia de la voluntad ducal respecto al derecho de disfrutar del terreno:

Yten se acordó que se acerca el tiempo de la sementera [...] y los Carrascales se deven senbrar por los vecinos desta villa para el aprovechamiento universal dellas y que por quanto el dicho Señor Corregidor en la residencia que tomó en esta villa mandó que no se senbrase sin liçencia de su Excelencia y aunque de la dicha sentençia está apelado por el acatamiento que deven a su Excelencia se acordó que vaya e no de los señores regidores desta villa con carta del consejo suplicando a su Excelencia de licençia para que se sienbren los dichos Carrascales e para que se le de salario a un boticario y que el dicho Señor Corregidor escriva sobre ambas cosas a su Excelencia. ${ }^{32}$

No es descartable, por tanto, al no conservarse actualmente los alcornoques y mojones descritos en el privilegio otorgado a los vecinos de San Juan el 22 de septiembre de $1484,{ }^{33}$ que Los Carrascales pudieran haber estado integrados en la época del descubrimiento de América en las tierras arrendadas a Briolanja Muñiz; sobre todo, si se tiene en cuenta que el espacio cultivado por la cuñada de Cristóbal Colón cruzaba por el carril que iba hacia la población de Trigueros.

Más al sur del sitio de Los Carrascales, en dirección hacia el estero de Juan de Coto y antes de llegar a El Montecillo, junto al puente elevado existente sobre la autopista A49 que comunica Huelva con Sevilla, pude localizar restos arqueológicos que indicaban un poblamiento en esta zona en el período colombino, ${ }^{34}$ lo que abría la posibilidad de tratarse de restos de viviendas anexadas a parcelas cultivadas como la que podría haber tenido Briolanja Muñiz en este sector; a pesar de ser una hipótesis inicial que

31 A mediados del siglo XVIII una parcela localizada en este lugar pertenecía a los bienes propios del «común de la villa»; concretamente de su extensión y características se dejaba constancia en el libro de fincas seculares: «Posee una pieza de veinte y siete fanegas y media de tierra de sembradura de secano de primera calidad, a el sitio del Carrasca(1) dos tiros de bala de la población, confronta [...] a el Norte con el Padrón de Carrascal, y a el Sur con el camino de la Carne [...]». Libro de fincas seculares del Catastro de Ensenada, San Juan del Puerto, 1752, AMSJP, 493, f. 739.

32 AMSJP, Actas Capitulares, 1, f. 16v-17r.

33 AMSJP, 43, s/f.

34 El yacimiento se encuentra dividido en dos mitades como consecuencia de haber sido atravesado por la autovía A49. 
requiere del hallazgo de nuevas fuentes que la corroboren en un futuro, sí se tiene certeza de que una vez analizado este yacimiento por el equipo de investigación de Arqueología de la Universidad de Huelva, fue confirmada la cronología bajomedieval-moderna de los materiales existentes en él. ${ }^{35} \mathrm{En}$ efecto, han aparecido en el mencionado yacimiento restos suficientes que testimonian su ocupación y habitabilidad: cerámicas vidriadas correspondientes a grandes recipientes, fragmentos de azul sobre blanco, trozos de ladrillo y alguna escudilla, entre otros. ${ }^{36}$

\section{El ejido o las «tierras que tenía Briolanja»}

La delimitación exacta del ejido del concejo de San Juan del Puerto presenta las dificultades lógicas que genera - después de haber transcurrido más de cinco siglos - la descripción efectuada por la administración ducal en el privilegio de 22 de septiembre de 1484, en el cual se establecían sus límites; ciertamente, en el citado documento se utilizaba como referencia varios alcornoques, una retamera, un lentisco y algunos mojones que actualmente han desparecido, lo que complica la identificación. Por tanto, la labor de reconstrucción histórica de su localización se encuentra, a priori, con evidentes obstáculos que se han tratado de salvar partiendo de elementos inamovibles como el estero de Juan de Coto y El Montecillo - situados en el extremo oeste en la zona limítrofe con el término municipal de Huelva-, y cruzando esta información con documentación cronológicamente posterior que pudiera establecer sus límites hacia el este antes de llegar a las viviendas del núcleo urbano de la localidad.

En cualquier caso, sí se tiene constancia de la solicitud realizada por el concejo municipal de San Juan del Puerto al duque de Medina Sidonia sobre la devolución de las tierras que habían sido entregadas «por merced» a Briolanja Muñiz — según se afirmaba en el privilegio otorgado el 20 de enero de $1493-,{ }^{37}$ pues los capitulares pretendían que volviesen a cumplir la función comunal original de beneficiar a los vecinos de San Juan y a las

35 Memoria científica inédita del «Proyecto de prospección superficial del término municipal de San Juan del Puerto (Huelva)», 31-33. Director del Equipo de Investigación «Urbanitas. Arqueología y Patrimonio» de la Universidad de Huelva: Dr. Juan Manuel Campos Carrasco. Director de la intervención: Dr. Javier Bermejo Meléndez. Agradezco a los mencionados investigadores los datos que me han proporcionado sobre el citado yacimiento para que pudiera hacer referencia a ellos en este artículo.

36 Idem.

37 AFCMS, 736, s/f. 
«bestias de los recueros» que transitaban por el lugar. A este respecto, no ha sido posible conocer la fecha concreta de la restitución del aprovechamiento del ejido debido a que las actas del cabildo municipal correspondientes a fines del siglo XV y gran parte del siglo XVI no se han conservado. No obstante, al menos antes de 1587 se hallaba restablecido su uso primigenio, tal como puede deducirse de un acuerdo capitular adoptado el 30 de enero de ese año, en el que se ordenaba que los «rocines y bestias de albarda $»^{38}$ no anduviesen por la dehesa ni fuera del «ejido que les está señalado». ${ }^{39}$

Por su parte, el hecho de no haber sido perennes algunos de los elementos de referencia que fueron utilizados para su delimitación en 1484 ha impedido saber con certeza si con posterioridad se produjeron modificaciones de la extensión del mencionado ejido, si bien el libro de fincas seculares del Catastro de Ensenada datado a mediados del siglo XVIII reseña su proximidad a los caminos de Huelva y de Gibraleón ${ }^{40}$ - tal como sucedía en la época colombina- y su límite en dirección este en torno a los corrales de las actuales calles Pozo Nuevo ${ }^{41}$ y Trigueros, ${ }^{42}$ y las tierras de regadío situadas junto a la calle Huelva. ${ }^{43}$ En este sentido, después de la consulta detallada del citado catastro se llega a la conclusión de que en el setecientos las huertas limítrofes con el ejido eran las que estaban localizadas más al oeste del núcleo urbano de San Juan del Puerto, concretamente las que se cultivaban en la calle Huelva y sus inmediaciones; de ahí que no se podría descartar que alguna de ellas se pudiera identificar con la denominada «huerta de Ruy López», citada como límite de las tierras que explotó la cuñada de Cristóbal Colón.

38 Según el diccionario de la Real Academia de la Lengua Española el significado del término albarda es: «pieza principal del aparejo de las caballerías de carga». Por tanto, el mandato precedente para que los caballos y bestias de carga estuvieran en este ejido suponía que había recobrado su finalidad contenida en el privilegio de 1484; es decir, el «proveimiento de las bestias del pueblo e de los recueros».

39 AMSJP, Actas Capitulares, 1, f. 144r. Otra resolución semejante acordaba el cabildo de la villa el 11 de febrero de 1589 cuando se reiteraba que las «jacas de albarda» debían estar en el ejido. AMSJP, 1, f. 198.

40 La cercanía del ejido a ambos caminos se aprecia en el siguiente fragmento documental: «pieza de tierra de siete fanegas de sembradura de secano de primera calidad entre los dos caminos distante de la población dos tiros de vala confronta [...] a Poniente con el Exido, a Norte con el camino de Gibraleón y al Sur con el camino de Huelva». Libro de fincas seculares del Catastro de Ensenada, San Juan del Puerto, 1752, AMSJP, 493, f. 748v.

41 Libro de fincas seculares del Catastro de Ensenada, San Juan del Puerto, 1752, AMSJP, 493 , f. 681 y 740 .

42 Ibidem, f. 561-562.

43 Ibidem, f. 331-332, 534-535, 569 y 689. 
Aun teniendo en cuenta los inconvenientes originados por las fuentes para determinar la extensión exacta de las tierras de Briolanja Muñiz, este hecho no ha sido óbice para conocer que su emplazamiento gozaba de una situación privilegiada al encontrarse en torno a un nudo de comunicaciones; en efecto, por sus inmediaciones pasaba la vereda que se dirigía al señorío de Gibraleón, el camino hacia Huelva, el carril en dirección a Trigueros que conectaba con Sierra Morena y Extremadura, el camino que enlazaba con la villa de Niebla en dirección a la ciudad de Sevilla, así como el estero de Juan de Coto que comunicaba con los puertos del río Tinto y, por tanto, con las rutas marítimas nacionales e internacionales.

En este contexto, la atractiva localización geográfica del terreno de su cuñada le pudo haber proporcionado a Cristóbal Colón un lugar de acogida tras su llegada desde Portugal y un potencial hogar para su hijo Diego - una vez fallecida su esposa Filipa Moniz-; sin duda, se encontraba perfectamente comunicado con las vías terrestres y de navegación, lo que podría haberle permitido al ilustre navegante regresar sin demasiadas dificultades tras los viajes que realizó por Castilla en la búsqueda de apoyos para su proyecto descubridor. Desde luego, la relación afectuosa mantenida por el Almirante con Briolanja y de esta con su sobrino — ratificada documentalmente con muestras de evidente cariño- pudo haber sido consecuencia de que la portuguesa se hubiera encargado del cuidado y tutelaje del niño mientras que negociaba y gestionaba el primer viaje a las Indias. ${ }^{44}$

44 A este asunto del cuidado del hijo primogénito del genovés por parte de Briolanja Muñiz se han referido varios historiadores. En efecto, el doctor Arranz afirmaba que los cuñados de Cristóbal Colón «podrían hacerse cargo de Diego mientras él iba a negociar su proyecto descubridor con los reyes de Castilla [...], recordar las relaciones futuras y el tratamiento que los Colón darán a Violante Muñiz, pues en la inusitada generosidad colombina de años después percibimos un pago se servicios prestados: servicios que pueden relacionarse perfectamente con el cuidado de Diego Colón antes de 1491» (Arranz, 1982, 43). Por su parte, el profesor Rumeu manifestaba que la versión de que el hijo mayor de Cristóbal Colón se quedó alojado en el monasterio de La Rábida fue una invención (a cuya tesis se sumaría también una década más tarde el mencionado Luis Arranz), y lo enunciaba de este modo: «Por esta circunstancia el autor de los capítulos de cabecera de la Historia del Almirante incurre en defectos que pudiéramos llamar menores. Más que supercherías se descubren fallos, mala información, invenciones intrascendentes, bien que incompatibles en absoluto con el supuesto responsable de la totalidad de la obra. La primera tergiversación que descubrimos se concreta a la entrada en Andalucía, por La Rábida. La Historia... se expresa así: "El Almirante, a fines del año 1484, con su niño don Diego, partió secretamente de Portugal..., y... entró en Castilla a probar la suerte que le estaba aparejada. Dejado, pues, el niño en un monasterio de Palos, llamado La Rábida, fue pronto a la corte de los Reyes Católicos...". La estancia en el monasterio franciscano, la entrega del vástago a los frailes — como si aquella casa de religiosos fuera un orfelinato- y la permanencia de Diego en el cenobio por espacio de varios años no tiene fundamento alguno» (Rumeu, 1970, 43). Al respecto, véase también: Varela, 1988, 47. Varela Marcos, 2005, 46. 
A este respecto, parece razonable la tesis de la doctora Consuelo Varela que considera que Diego Colón residió en San Juan del Puerto atendido por sus tíos durante parte de su infancia; así lo expresaba:

Cuando Cristóbal Colón llegó a Andalucía por primera vez procedente de Portugal en 1485, la Muñiz estaba casada con un aragonés, Miguel Muliart, y residía en San Juan del Puerto, muy cerca de Huelva, y al ladito del Monasterio de La Rábida; allí, en su casa y a su cuidado, debió de quedar Diego. El genovés nunca olvidaría ese favor. ${ }^{45}$

Por último, junto a un potencial lugar de residencia para su hijo primogénito, la condición de cruce de caminos de San Juan del Puerto y del entorno de las tierras que cultivaba Briolanja Muñiz le proporcionaba a Cristóbal Colón la posibilidad de establecer contactos con el duque de Medina Sidonia ${ }^{46}$ y con sus criados en relación con la empresa descubridora. Precisamente, el ofrecimiento que hizo del proyecto a la casa ducal entraba dentro de la lógica atendiendo a que este linaje había participado durante décadas en las navegaciones a las Islas Canarias y tenía la experiencia que le había proporcionado la obtención de las tierras africanas comprendidas entre el cabo de Agüer y el de Bojador gracias a una concesión de Juan II de Castilla. ${ }^{47}$ A este respecto tampoco se puede olvidar que Martín Alonso Pinzón — capitán de la carabela Pinta y prestigioso marino de la zonaaparecía registrado en un documento de 1479 relativo a la venta de un dozavo de Palos de la Frontera como regidor, siendo contabilizado entre los «criados» del Guzmán que asistieron a su toma de posesión en la iglesia de San Jorge el 27 de enero de ese mismo año. ${ }^{48}$ En este sentido, se dispone de referencias sobre la presencia de Enrique de Guzmán en las proximidades de los terrenos que unos años más tarde fueron arrendados a la cuñada del genovés; concretamente, el cronista Barrantes Maldonado relataba del siguiente modo los testimonios recogidos sobre un presunto intento de asesinato del titular del condado de Niebla en 1478 mientras que realizaba

45 Varela, 1992, 85.

46 A estos contactos entre Enrique de Guzmán y el genovés se han referido diferentes historiadores. Entre otros: Manzano, 1989, 170. Serrera, 2011, v. 2, 57. Por su parte, el padre Las Casas también reseñaba la oferta realizada por Colón al duque de Medina Sidonia: «como tuviese noticia de las riquezas y magnanimidad del duque de Medina Sidonia D. Enrique de Guzmán, el cual, por aquella causa, obraba cosas egregias y de señor de gran magnificencia [...], así que propuesto ante el dicho duque su negocio, Cristóbal Colón, o porque no lo creyó, o porque no entendió la grandeza de la demanda, o porque, como estaban ocupados todos los grandes del Reino, mayormente los de Andalucía con el cerco de la ciudad de Granada». Las Casas, 1986, v. 1, 163.

47 Verlinden y Pérez-Embid, 2006, 51-52.

48 AFCMS, 734, s/f. Documento citado por Ladero, 2015, 284. 
actividades cinegéticas en San Juan, dentro del marco de la crisis sucesoria castellana y antes de firmarse el tratado de Alcaçovas-Toledo con Alfonso V de Portugal:

E como el duque don Henrrique salió de Sevilla, tan enojado de la Reina e del Rey, por el mal galardón que le avían dado por los muchos serviçios que les avía hecho, tuvieron el Rey é la Reina temor que, como era tan gran señor é de tantos puertos de mar é tan rico, con el enojo que llevava no hiziese algún movimiento en el reino; e dizen algunos quel Rey sabiendo como el Duque Don Henrrique estava en San Juan, un pueblo del condado, e andava por allí a caça, que mandó á Diego de Merlo, asistente de Sevilla, e á Don Lorenço, hermano del marqués de Cádiz, con çinquenta lanças para que le matasen e otras doçientas en socorro; de lo qual siendo el duque avisado por una espía que prendió, mandó a Perseval de Sotomayor, capitán de çien lanças de guarda quel Duque traía contino, que saliese á ellos, y mandó aperçibir la tierra, y el Duque como era tan animoso, cavalgó en una mula aquel día, e salióse a caça con solos sus caçadores e sin armas. Quando Diego de Merlo supo quel trato era descubierto, con grandísimo temor del Duque, vuelve las riendas é vase á Sevilla. ${ }^{49}$

Aunque no han sido probadas las sospechas de Enrique de Guzmán sobre que este supuesto complot para su asesinato hubiese sido ordenado por los Reyes Católicos, no es menos cierto que el episodio se desarrolló en San Juan y que a partir de 1481 generó diversa documentación oficial en la que intervinieron el secretario real Fernán Álvarez de Toledo, Diego de Oyón — criado del duque — , y los propios monarcas. ${ }^{50}$

Por otro lado, de la relación directa de la casa ducal con estos parajes daba cuenta un acuerdo del concejo municipal de San Juan del Puerto de 1590 - evidentemente posterior a la época colombina - en el que se dejaba constancia de la existencia de una casa de propiedad del duque en el Pradillo, ${ }^{51}$ la cual podría haber sido utilizada por los Medina Sidonia en sus cacerías o durante cortas estancias, precisamente en un sitio localizado junto al camino que enlazaba su término municipal con la villa de Huelva durante la Edad Moderna. ${ }^{52}$

En cualquier caso, como se ha podido comprobar, el antiguo ejido disfrutado por la familia de Cristóbal Colón poseía un emplazamiento geográfico envidiable, puesto que se encontraba a medio camino de los señoríos de

49 Barrantes, 1857, 304-305.

50 Libro de cartas reales de la Casa de Medina Sidonia con tres documentos fechados en Valencia el dos y el veintitrés de diciembre de 1481. Citados en Ladero, 2015, 224-226.

51 Así puede deducirse del acuerdo adoptado el 6 de octubre de 1590: «y que por el mesmo tiempo [seis años] e paga se ar[ri]ende el Pradillo de junto a la Casa del Duque», AMSJP, 1, f. 256.

52 Así, al menos, consta en el Libro de fincas eclesiásticas del Catastro de Ensenada, San Juan del Puerto, 1752, AMSJP, 494, f. 435. 
Niebla y de Huelva, a 60 kilómetros de la frontera con Portugal, a 82 kilómetros de la ciudad de Sevilla y, además, junto a un estero del río Tinto que los conectaba con las rutas marítimas atlánticas y mediterráneas.

\section{A modo de conclusión}

Los resultados de esta investigación permiten conocer emplazamientos geográficos inéditos del proceso de gestación del descubrimiento de América. Además, el hallazgo de nuevos documentos y su cruzamiento con otras fuentes ha posibilitado la localización de las coordenadas geográficas concretas del lugar donde se encontraban las tierras arrendadas por la hermana de la mujer de Cristóbal Colón en San Juan del Puerto, contribuyendo así a la delimitación de un sitio histórico de carácter colombino que como consecuencia del trabajo de indagación efectuado ha permitido definir determinados límites tales como el estero de Juan de Coto o El Montecillo. A este respecto, se ha demostrado que la finca estaba situada en un enclave privilegiado en torno a un nudo de comunicaciones, junto a un estero del río Tinto que la conectaba con las rutas marítimas nacionales e internacionales y también inmediata a un conjunto de vías terrestres que la enlazaban con Sierra Morena y la ruta de la Plata, con las localidades limítrofes con Portugal y con la ciudad de Sevilla, lo que facilitaba al célebre descubridor un lugar de acogida para él y su hijo Diego tras su venida desde el reino lusitano, y que además le proporcionaba diversas conexiones para negociar la participación de otros marinos de los puertos del entorno en la organización de la expedición a América o, en su caso, regresar sin demasiadas dificultades a las tierras explotadas por sus parientes tras haber realizado las gestiones necesarias ante la corte castellana, los duques de Medina Sidonia o de Medinaceli, con quienes se comunicó en la búsqueda de apoyos para su proyecto ultramarino.

Por último, esta investigación ratifica que los cuñados de Colón — partícipes del flujo migratorio que llegó desde el reino de Portugal- se integraron en el proceso de repoblación de esta nueva localidad promovido por los duques de Medina Sidonia mediante la carta puebla otorgada el 10 de enero de 1468 y una serie de privilegios datados en las décadas posteriores; por tanto, pudieron haberse acogido a algunas de las atractivas ventajas concedidas por los Guzmanes en materia de exenciones fiscales y actividades comerciales, entre otras. 


\section{Referencias bibliográficas}

Anasagasti Valderrama, Ana María y Rodríguez Liáñez, Laureano, Niebla y su tierra en la Baja Edad Media. Historia y documentos, Huelva, Diputación de Huelva, 2006, 2 vols.

Arranz, Luis, Don Diego Colón, Madrid, Instituto Gonzalo Fernández de Oviedo, CSIC, 1982.

Aznar Vallejo, Eduardo, «La expedición de Charles de Valera a Guinea. Precisiones históricas y técnicas», En la España Medieval, 25, Madrid, 2002, 403-423.

Barrantes Maldonado, Pedro, Ilustraciones de la Casa de Niebla, en Memorial Histórico Español: Colección de documentos, opúsculos y antigüedades, Madrid, Real Academia de la Historia, 1857, tomos IX y X.

Del Barco y Gasca, Antonio Jacobo, Dissertación histórico geográphica sobre reducir la antigua Onuba a la villa de Huelva, Sevilla, Imp. Joseph Padrino, 1755.

Galán Parra, Isabel, Las ordenanzas ducales del año 1504. Administración y economía en los señoríos de los duques de Medina Sidonia, Huelva, Ayuntamiento de Almonte, 2004.

Gil, Juan, Los conversos y la Inquisición sevillana, Sevilla, Universidad de Sevilla, Fundación El Monte, 2001, vol. 5.

Gould, Alicia B., Nueva lista documentada de los tripulantes de Colón en 1492, Madrid, Real Academia de la Historia, 1984.

González Cruz, David, «Fundación de la villa de San Juan del Puerto: de la repoblación señorial a través de carta puebla a la confirmación ducal de sus privilegios (1468-1551)», en González Cruz, David (dir.), Cinco siglos de historia de la villa de San Juan del Puerto, 1468-1992. De la tradición marítima al proceso de industrialización, Huelva, Ayuntamiento de San Juan del Puerto, 1992, 19-42.

González Cruz, David, «El puerto de San Juan en tiempos del descubrimiento de América y la expansión atlántica», en González Cruz, David (coord.), Descubridores de América. Colón, los marinos y los puertos, Madrid, Sílex Ediciones, 2012, 201-243.

González Cruz, David, «Contribuciones y estrategia fiscal de los Reyes Católicos en el entorno de los puertos del río Tinto durante el proceso de gestación y de financiación del primer viaje colombino», Historia, 49, Santiago de Chile, 2016, 111-132.

González Gómez, Antonio, Moguer en la Baja Edad Media (1248-1538), Huelva, Diputación Provincial de Huelva, 1977.

Izquierdo Labrado, Julio, «Palos y la comunidad franciscana de La Rábida en la época del descubrimiento de América», en González Cruz, David, Descubridores de América. Colón, los marinos y los puertos, Madrid, Sílex Ediciones, 2012, 47-74.

Irving, Washington, Mi viaje a los Lugares Colombinos. España. 1828, Almería, Casa Sinapia Ediciones, 2012. 
Ladero Quesada, Miguel Ángel, «Palos en vísperas del Descubrimiento», Revista de Indias, 38, Madrid, 1978, 471-506.

Ladero Quesada, Miguel Ángel, Guzmán. La casa ducal de Medina Sidonia en Sevilla y su reino (1282-1521), Madrid, Dykinson, 2015.

Las Casas, Bartolomé de, Historia de las Indias, Caracas, Biblioteca Ayacucho, 1986, vol. 1.

Las Casas, Bartolomé de, Historia de las Indias, Madrid, Alianza Editorial, 1994, vol. 3.

León Guerrero, María Montserrat, El segundo viaje colombino, Tesis doctoral presentada en la Universidad de Valladolid, 2000. http://www.cervantesvirtual. com/obra/el-segundo-viaje-colombino-0/ [Consultado: 20/04/2016].

Manzano Manzano, Juan, Cristóbal Colón. Siete años decisivos de su vida, $1485-$ 1492, Madrid, Ediciones Cultura Hispánica, 1989.

Muro Orejón, Antonio (ed.), Pleitos Colombinos. IV. Probanzas del Fiscal (15121515), Sevilla, Escuela de Estudios Hispano-Americanos, CSIC, 1989.

Ortega, Ángel, La Rábida: historia documental crítica, Sevilla, Imprenta y Editorial San Antonio, 1925.

Pérez de Tudela Bueso, Juan (dir.), Colección Documental del Descubrimiento (1470-1506), Madrid, Editorial Mapfre, 1994, vol. 1.

Ramírez Copeiro del Villar, Jesús, «El ferrocarril de Buitrón. Las compañías inglesas y el transporte de minerales a través del puerto de San Juan (1867-1969)», en González Cruz, David (dir.), Cinco siglos de historia de la villa de San Juan del Puerto, 1468-1992. De la tradición marítima al proceso de industrialización, Huelva, Ayuntamiento de San Juan del Puerto, 1992, 211-233.

Romero Macías, Emilio (dir.), Los ferrocarriles en la provincia de Huelva. Un recorrido por el pasado, Huelva, Universidad de Huelva, 2007.

Rumeu de Armas, Antonio, Hernando Colón, historiador de América, Madrid, Real Academia de la Historia, 1970.

Serrera Contreras, Ramón María, «El golfo de Cádiz como espacio geográfico de proyección para la empresa del Descubrimiento», en García Cruzado, Eduardo (coord.), Actas de las Jornadas de Historia sobre el Descubrimiento de América, Sevilla, Universidad Internacional de Andalucía y Ayuntamiento de Palos de la Frontera, 2011, vol. 2, 189-210.

Varela, Consuelo, Colón y los florentinos, Madrid, Alianza Editorial, 1988.

Varela, Consuelo, Cristóbal Colón. Retrato de un hombre, Madrid, Alianza Editorial, 1992.

Varela, Consuelo, La caída de Cristóbal Colón. El juicio de Bobadilla, Madrid, Marcial Pons, 2006.

Varela Marcos, Jesús, Colón y Pinzón, descubridores de América, Valladolid, Universidad de Valladolid, 2005.

Varela Marcos, Jesús y León Guerrero, María Montserrat, El itinerario de Cristóbal Colón (1451-1506), Valladolid, Universidad de Valladolid, 2003.

Verlinden, Charles y Pérez-Embid, Florentino, Cristóbal Colón y el descubrimiento de América, Madrid, Ediciones Rialp, 2006. 